 \\ BY \\ R.E. HATCHER AND M. OKABAYASHI
} \\ MARCH 1995
}
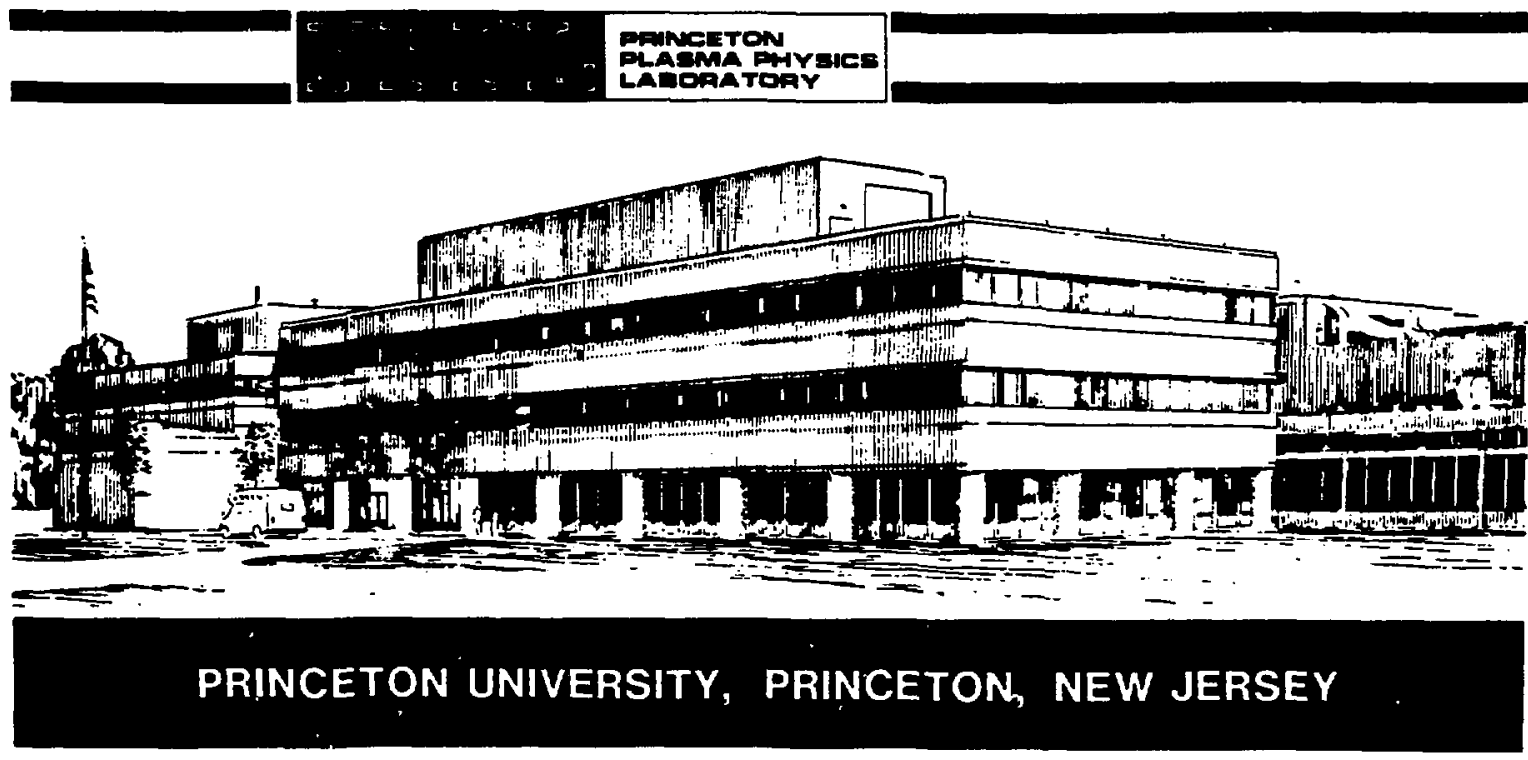


\section{NOTICE}

This report was prepared as an account of work sponsored by an agency of the United States Government. Neither the United States Government nor any agency thereof, nor any of their employees, makes any warranty, express or implied, or assumes any legal liability or responsibility for the accuracy, completeness, or usefulness of any information, apparatus, product, or process disclosed, or represents that its use would not infringe privately owned rights. Reference herein to any spe ific commercial produce, process, or service by trade name, trademark, manufacturt ; or otherwise, does not necessarily constitute or imply its endorsement, recommendation, or favoring by the United States Government or any agency thereof. The views and opinions of authors expressed herein do not necessarily state or reflect those of the Jnited States Government or any agency thereof.

\section{NOTICE}

This report has been reproduced from the best available copy. Available in paper copy and microfiche.

Number of pages in this report: 32

DOE and DOE contractors can obtain copies of this report from:

Office of Scientific and Technical Information

P.O. Box 62

Oak Ridge, TN 37831 ;

(615) 576-8401.

This report is publicly available from the:

National Technical Information Service

Department of Commerce 5285 Port Royal Road

Springfield, Virginia 22161

(703) 487.4650 


\title{
Integrated Shell Approach To Vertical Position Control On PBX-M
}

\author{
R. E. Hatcher and M. Okabayashi \\ Princeton Plasma Physics Laboratory \\ P.O. Box 451, Princeton, NJ 08543
}

\begin{abstract}
The PBX-M device produces highly shaped discharges that, because of the negative external magnetic field decay index required, are vertically unstable. Vertical positional stability in PBX-M has been achieved by airectly controlling the $\mathbf{n}=0$ component of the eddy current in the passive shell instead of the commonly used function of magnetic flux signals. Because the active coil is controlled via currents in the passive shell we call this an "integrated shell" approach to vertical position control. We present results of these experiments and make comparisons between the two methods of control.
\end{abstract}

\section{DISCLAIMER}

\begin{abstract}
This report was prepared as an account of work sponsored by an agency of the United States Government. Neither the United States Government nor any agency thercof, nor any of their employees, makes any warranty, express or implied, or assumes any legal liability or responaibility for the accuracy, completeness, or usefulness of any informetion, apparatus, product, of process disclosed, or represents that its use would not infringe privately owned rights. Reference berein to any specific commercial product, process, or service by trade name, trademark, manufacturer, or otherwise does not necessarily constitute or imply its endorsement, recommendation, or favoring by the United States Government or any agency thereor. The views and opinions of authors expressed herein do not necessurily state or reffect those of the United States Government or any agency thereof.
\end{abstract}




\section{Introduction}

Recent experimental and theoretical advances have demonstrated that high plasma pressure regimes can be achieved by increasing the non-circularity of the plasma cross-section. D-shaped, non-circular, configurations are now considered to be promising candidates for optimizing the tokamak concept toward economically attractive fusion reactors. Larger devices, such as TPX and ITER, have been designed to maximize both the elongation and triangularity of the plasma cross-section. A serious problem encountered in highly non-circular designs is an associated vertical instability. Illustrative of the need for effective vertical control is the recent observation of the Vertical Displacement Event (VDE)[1]. In the VDE a vertically displaced plasma, without a coincident reduction in current, causes significant motion of the vacuum vessel. As a consequence, plasma facing components have been severely damaged by halo currents flowing through the plasma edge and vacuum vessel metallic surfaces.

On PBX-M vertical position control of elongated plasma configurations is accomplished by a combination of passive conducting elements and an active coil system that produces the radial field required to maintain the plasma vertical position. The role of the passive elements are to stabilize the plasma on MHD Alfvén time scale $(\sim \mu \mathrm{s})$ leaving the plasma unstable on the $L / R$ time of the passive elements $(\sim 30-100 \mathrm{~ms})$. The active system compensates the flux loss due to the finite resistivity of the passive elements on the slow time scale. The passive conducting elements used (separately or in combination) in various devices are: the metallic vacuum vessel structure, additional poloidally wound coils, and a close-fitting passive shell.

An approach utilizing a close-fitting conducting shell is sech 25 an attractive option, since the shell can also reduce the growth rate of sxternal kinks that are considered a strong candidate for the disruption mechanism. In PBX-M[2, 3], a five-element passive structure tightly covers $70 \%$ of the plasma surface, and in the proposed TPX device[4], the closely fitting conducting shell located on the "outboard" side should stabilize the $\mathrm{n}=0,1$, and 2 modes. In the shell arrangement, measurements of eddy currents on the shell, $n=1$ and 2, can be used to discern global MHD activity[2], and the $n=0$ component can be used by a vertical position control system.

Here, we propose an "integrated shell" approach for vertical position con- 
trol that uses the $n=0$ component of the eddy current on the close-fitting conducting shell to achieve a more stable control. In order to simplify the discussion we assume a symmetric divertor configuration with the plasma held on the mid-plane. ${ }^{1}$ With plasma motion, the eddy current appearing on the passive shell consists of the current due to the plasma motion itself and that due to changes in the current through the active coil circuit. As discussed later, if the $n=0$ component of the shell eddy current is kept at zero, the plasma position will remain on the mid-plane. In this approach, the plasma position is included indirectly and the active coil is controlled to maintain a "zero $n=0$ induced component" of the shell eddy current. Because of this, the active coil can be considered as a part of the passive shell structure, and the system works as an integrated virtual flux-conserving shell. Thus, we coin the term "integrated shell" approach.

This integrated shell scheme is similar to the MHD stabilization of a reversed toroidal pinch proposed by Bishop[5], where localized eddy current patterns are controlled using localized sensing loops with active coils tightly coupled to the passive shell. There are several advantages to controlling the passive shell eddy currents applicable to fusion reactors. Firstly, a reduction of the current on the passive shell, or on the surrounding vacuum vessel structure, will reduce the heat generated in these components benefiting long pulse devices. Secondly, with the integrated shell approach, the system's response is predominantly damped exponential in character without the inclusion of derivative action in the control law. Thirdly, the global eddy current is less vulnerable to contamination by noise and non-ideal magnetic flux sources. The proof-of-principle study of the integrated shell concept, as recently carried out on PBX-M, is the subject of this paper.

We describe in Section 2 the basics of plasma vertical position control and compare the standard and integrate shell approaches. We present an analysis of the two methods, in the simplest case, and discuss the dynamic character of the solutions. Section 3 describes the application of vertical position control on $\mathrm{PBX}-\mathrm{M}$, and presents results from recent plasma experiments illustrating the effectiveness of the integrated shell method in practice. Section 4 contrasts the two methods in detail. Finally, we will summarize

\footnotetext{
${ }^{1}$ For an asymmetric divertor configuration, or for configurations with the plasma held off the mid-plane, the method can be modified by introducing a time varying offset proportional to the plasma current.
} 
our results and offer suggestions for further study.

\section{Active Plasma Vertical Position Control}

Figures $1 \mathrm{a}$ and $1 \mathrm{~b}$ illustrate schematically the commonly used "explicitz" [7] and integrated shell approaches to vertical position control. In both instances the plasma-active and plasma-passive interactions are identical. The following set of equations describe either system.

$$
\begin{gathered}
L_{a} \dot{I}_{a}+R_{a} I_{a}+M_{p s, a} \dot{I}_{p s}+M_{a, p l}^{\prime} I_{p l} \dot{Z}_{p l}=V_{a} \\
V_{a}=K_{p}\left(\alpha^{t}-\alpha^{o}\right)+K_{d} \frac{d}{d t}\left(\alpha^{t}-\alpha^{o}\right) \\
\frac{d}{d t} \Phi_{p s}+R_{p s} I_{p s}=0 \\
\Phi_{p s}=M_{p s, a} I_{a}+L_{p s} I_{p s}+M_{p s, p l}^{\prime} I_{p l} Z_{p l} \\
M_{a, p l}^{\prime} I_{a}+M_{p s, p l}^{\prime} I_{p s}-M_{e x t, p l}^{\prime \prime} I_{p l} Z_{p l}=0
\end{gathered}
$$

where

$I=$ current

$\mathrm{V}=$ voltage

$\mathrm{L}=$ self inductance

$\mathbf{R}=$ lumped parameter resistance

$\mathrm{a}=$ active feedback system

ps $=$ passive shell system

$\dot{\mathbf{x}}$ is the derivative of $\mathrm{x}$ with respect to time

$\mathrm{M}_{\mathrm{x}, \mathrm{y}} \stackrel{\text { def }}{=}$ mutual inductance between systems $\mathrm{x}$ and $\mathrm{y}$.

$\mathrm{M}_{\mathrm{ps,a}}=$ mutual inductance between the $\mathrm{n}=0$ current path

on the passive shell and the active coil system. 


$$
\begin{aligned}
& \Phi \stackrel{\text { def }}{=} \text { component }{ }^{f} \text { poloidal flux } \\
& \mathrm{x}^{\prime} \text { is the derivative of } \mathrm{x} \text { with respect to } \mathrm{z} \\
& \mathrm{pl}=\text { plasma } \\
& \mathrm{Z}_{\mathrm{pl}}=\text { plasma vertical position } \\
& \mathrm{K}_{\mathrm{p}}=\text { proportional gain } \\
& \mathrm{K}_{\mathrm{d}}=\text { derivative gain } \\
& \text { ext }- \text { refers to the external coil system } \\
& \alpha^{\mathrm{t}}=\text { target value of the control variable } \\
& \alpha^{\circ}=\text { observed value of the control variable }
\end{aligned}
$$

Equations (1) and (3) are Kirchoff's voltage law for the active and passive systems respectively. Equation (2) describes the feedback law, Eq. (4) describes the induced flux on the passive stabilizer, and Eq. (5) is a statement of the radial field balance relationship.

When the plasma moves off the mid-plane a radial field is generated according to Eq. (5). The motion induces voltage on both the passive and active coil systems $\left(V_{p s}=M_{p s, p l}^{\prime} I_{p l} Z_{p l}\right.$ and $\left.V_{a}=M_{a, p l}^{\prime} I_{p l} Z_{p l}\right)$ producing stabilizing radial fields that act to oppose the motion of the plasma. This action by the passive stabilizer, and to a far lesser extent the active coil, increases the time scale of the vertical instability from the ideal MHD time scale to one similar to the effective $L / R$ time of the combined passive and active coil systems. The feedback system provides a controllable radial field that is used to actively control the plasma's vertical position. The feedback system is used to move the plasma back to the mid-plane, or alternatively can be used to hold it in a vertically asymmetric configuration.

In the explicit-z approach, the vertical position of the plasma centroid relative to the mid-plane, $I_{p l} Z_{p l}$, is the control variable. An estimate of $I_{p l} Z_{p l}$ is typically constructed from magnetic flux and/or field measurements. The feedback system causes the voltage $\mathrm{K}_{\mathrm{p}} \mathrm{I}_{\mathrm{pl}}\left(\mathrm{Z}_{\mathrm{pl}}^{\mathrm{t}}-\mathrm{Z}_{\mathrm{pl}}^{\mathrm{o}}\right)+\mathrm{K}_{\mathrm{d}} \frac{\mathrm{d}}{\mathrm{dt}} \mathrm{I}_{\mathrm{pl}}\left(\mathrm{Z}_{\mathrm{pi}}^{\mathrm{t}}-\mathrm{Z}_{\mathrm{pl}}^{\mathrm{o}}\right)$ to appear at the terminals of the active coil system, which generates a stabilizing radial field of magnitude $M_{a, p l}^{\prime} I_{2}$. It should be noted that the active system also couples to the passive system, and that the coupling is such that it lessers the effect of the passive system by producing a destabilizing radial field. 
In the integrated shell approach, the $n=0$ component of the passive shell current is used as the control variable. If we can maintain $I_{p s} \approx 0$ the plasma should stay nearly centered on the mid-plane. Again, the feedback system is used to produce the stabilizing radial field. In this case we only use the term proportional to the difference between the target and observed value for effective control. This is because the roots of the system's characteristic equation are real for all positive values of $K_{p}$ as discussed later. The voltage applied to the active coil system is $\mathrm{K}_{\mathrm{p}}\left(\mathrm{I}_{\mathrm{ps}}^{\mathrm{t}}-\mathrm{I}_{\mathrm{ps}}^{\mathrm{o}}\right)$, which generates a radial field of magnitude $\mathrm{M}_{2, \mathrm{pl}}^{\prime} \mathrm{I}_{\mathbf{2}}$.

\subsection{Circuit Analysis}

The stability of a passive system assisted by an active system depends on the relative strengths, and derivatives thereof, of the mutual magnetic coupling between the passive system, the active coil system, and the plasma vertical position. Using Laplace transform techniques we can derive a transfer function relating $I_{p l} z_{p l}$ to the remaining variables $\left(I_{p s}\right.$ and $\left.I_{a}\right)$. The global behavior of the system is determined by the roots of the denominator of this transfer function (the characteristic equation). Following the treatment by Lazarus et al.[6], we focus our efforts on the behavior of the roots to the characteristic equation as the gain is varied. Standard transform techniques applied to Eqs. 1 - 5 with $K_{d}=0$, i.e., proportional control only, yields the following characteristic equation [8].

$$
f(s)=A s^{2}+\left[B_{0}+K_{p} B_{1}\right] s+\left[C_{0}+K_{p} C_{1}\right]=0
$$

where $s$ is the Laplace transform variable (see Appendix). The analysis of the case $K_{d} \neq 0$, proportional plus derivative control, has been discussed previously [6-8] and will not be considered here. From stability considerations it is obvious that the proportional gain, $K_{p}$, must be negative in the integrated shell method and positive in the explicit-z method. To simplify our analysis and discussions, the proportional gain for the integrated shell method is made expressly negative by introducing a minus sign in Eq. 2. With these sign conventions $V_{2}=-K_{p}\left(I_{p s}^{t}-I_{p s}^{o}\right)$ for the integrated shell method and $V_{\mathrm{a}}=\mathrm{K}_{\mathrm{p}}\left(\mathrm{Z}_{\mathrm{pl}}^{\mathrm{t}}-\mathrm{Z}_{\mathrm{pl}}^{\mathrm{o}}\right)$ for the explicit-z method. In what follows we only consider the case of $K_{p}>0$ for both the explicit- $Z$ and the integrated shell methods. 
The dynamic behavior of the system is determined by the values of the roots of the characteristic equation. Some insight into the different ways that gain affects the roots for both explicit-z and integrated-shell methods can be obtained by comparing the coefficients of the equation for both methods. The coefficient $A$ is the same for both schemes, and does not depend on the gain $K_{p}$. The terms $B_{1}$ and $C_{1}$ that multiply the gain $K_{p}$ provide insight into the differences between the two schemes.

$$
B_{1}=-\frac{1}{L_{a} L_{p s}}\left[\frac{M_{p s, a} M_{p s, p l}^{\prime}}{M_{e x t, p l}^{\prime \prime}}-\frac{L_{p s} M_{a, p l}^{\prime}}{M_{e x t, p l}^{\prime \prime}}\right]
$$

for explicit-z control and

$$
B_{1}=\frac{1}{L_{a} L_{p s}}\left[M_{p s, a}+\frac{M_{a, p l}^{\prime} M_{p s, p l}^{\prime}}{M_{e s t, p l}^{\prime \prime}}\right]
$$

for integrated shell control, while

$$
C_{1}=\frac{R_{p s}}{L_{a} L_{p s}} \frac{M_{a, p l}^{\prime}}{M_{e x t, p l}^{\prime \prime}}
$$

for explicit-z control and

$$
C_{1}=0
$$

for integrated shell control. The most significant difference between the equations for the two schemes is that $C_{1}=0$ for the integrated shell scheme.

We can rearrange Eq. (6) so that it resembles the usual feedback equation $1+\mathrm{G}(\mathrm{s}) \mathrm{H}(\mathrm{s})=0$. By doing this we can apply the techniques of classical control theory to analyze the behavior of the roots as the gain is varied. The quantity $\mathrm{G}(\mathrm{s}) \mathrm{H}(\mathrm{s})$ is called the loop transfer function. The poles (zeros) of $\mathrm{G}(\mathrm{s}) \mathrm{H}(\mathrm{s})$ are the roots of the denominator (numerator) of $\mathrm{G}(\mathrm{s}) \mathrm{H}(\mathrm{s})$. The poles of $\mathrm{G}(\mathrm{s}) \mathrm{H}(\mathrm{s})$ are the roots of Eq. (6) when $\mathrm{K}_{\mathrm{p}}=0$. These are the eigenvalues of the system without feedback. At the opposite extreme the zeros of $\mathrm{G}(\mathrm{s}) \mathrm{H}(\mathrm{s})$ are the roots of Eq. (6) in the limit as $K_{-} \rightarrow \infty$.

For both the explicit-z and the integrated shell approach the poles of $\mathrm{G}(\mathrm{s}) \mathrm{H}(\mathrm{s})$ are real and opposite in sign (i.e., there is one stable and one unstable eigenmode). This is to be expected as the system is unstable without feedback. The difference in behavior of the roots as a function of gain for the 
two schemes occurs because of differences in the locations of the finite zeros of $\mathrm{G}(\mathrm{s}) \mathrm{H}(\mathrm{s})$. In the explicit-z scheme the finite zero occurs at

$$
s=-\frac{R_{p s}}{L_{p s}}\left[1-\frac{M_{a, p s} M_{p s, p l}^{\prime}}{L_{p s} M_{a, p l}^{\prime}}\right]^{-1} .
$$

The quantity in brackets is always positive, making the overall sign negative. For the integrated shell scheme the finite zero is located at $s=0$.

Figure 2 shows the behavior of the roots for each method, given the parameters of the $\mathrm{PBX}-\mathrm{M}$ device, as the gain is varied. For both cases, when the gain is small, we have two real roots of opposite sign, the positive root being greater in magnitude. As the gain increases, the roots in the explicit-z system coalesce to form a double root that becomes a complex conjugate pair as the gain is increased further. The double root can occur either on the positive or negative real axis. If the double root occurs on the negative real axis, it occurs very near to the origin. Depending on the location of the double root, we will initially get exponentially damped or growing sinusoidal modes. As the gain is increased further, we get two exponentially damped sinusoidal solutions. At a much higher value of gain, the roots are both real and negative and the modes are damped exponentials. In limit as $K_{p} \rightarrow \infty$, one root approaches negative infinity and the other converges to the value of the loop transfer function zero. In the integrated shell scheme a slight increase in gain above zero moves the positive real root close to zero and the negative real root far from zero. Because of the zero of the loop transfer function at $s=0$ the roots are never complex. The magnitude of the positive root can be made as close to zero as desired merely by increasing the gain $K_{p}$. Because of this the dominant root is the negative one and the behavior of the system is primarily due to the eigenmode associated with it. There is a question as to whether or not the growth time for the positive root can practically be made large enough to provide for stable conditions on the time scale of the experiment. Although simple calculations confirm the assertions above this question can best be answered by results from experiments.

\section{Vertical Position Control On PBX-M}

PBX-M is a medium size tokamak with $1.65 \mathrm{~m}$ major radius and midplane plasma width of $0.3 \mathrm{~m}$. It is capable of producing strongly indented con- 
figurations of up to $30 \%$. This configuration is intrinsically unstable against the $n=0$ vertical displacement, and for this reason the passive stabilizing shell surrounds the plasma surface by as much as $70 \%$ [2]. The PBX device, which operated prior to $\mathrm{PBX}-\mathrm{M}$, also incorporated a passive shell that partially surrounded $<30 \%$ the plasma surface to help with the vertical instability $(n=0)$. The extended coverage passive shell on PBX-M, although primarily installed to help suppress the ideal MHD surface kink mode $(n=1)$, has also improved the passive response to vertical plasma motion over relative to the PBX configuration. This is due to the higher mutual coupling between the new outboard plates and the plasma, and the higher current density near the outboard plates relative to the inboard ones. The PBX-M device has five independently-controlled poloidal field coil systems, soine of which are located immediately behind the passive stabilizing shell in order to produce the higher moment magnetic field patterns required to form the highly non-circular plasma. Thus, slight misalignment of the poloidal field coils near the observation flux points can result in a substantial asymmetric signal on the flux loop that is used by the feedback system.

Two sets of active coils are located outside the vacuum vessel. Each pair is saddle-connected and are located on the inboard $(R=0.667 \mathrm{~m})$ and outboard $(\mathrm{R}=2.25 \mathrm{~m})$ sides of the plasma discharge. The radial field produced is close to uniform over the plasma cross-section. The maximum field strength is $20 \mathrm{G}$ near the horizontal mid-plane at $2 \mathrm{kA}$ excitation current. The field penetration time $(\mathrm{L} / \mathrm{R})$ is $\approx 100-150 \mathrm{~ms}$. The power supply is a $2 \mathrm{kA} / 50 \mathrm{~V}$ linear voltage amplifier.

Flux observation points are on the passive shell surface facing the plasma surface. As shown in Fig. 3, the flux values are constructed by combining two sets of flux loops: toroidally continuous flux loops located behind the passive shell, and toroidally segmented loops located in front of the passive shell. In the explicit- $z$ scheme, these signals are vulnerable to misalignments of flux loops, misalignment of poloidal field coils, localized eddy fields (especially the segmented loops), unidentified eddy currents from the $\mathrm{OH}$ flux swing and its time derivatives, and the toroidal field. In this scheme we apply DC compensation for the five poloidal field coil system currents, the $\mathrm{OH}$ current, and the toroidal field current. The difference between the flux measured above and below the mid-plane is used as an estimate of the plasma vertical position. Operation of this system was reported in [8]. Typical values of the 
parameters for both methods of control are listed in Tables 1 and 2.

\section{1. $P B X-M$ Passive Stabilizer System}

The passive plates are poloidally segmented to provide for equilibrium field penetration (Fig. 3). The typical value for the field penetration time is $10-20 \mathrm{~ms}$, which is comparable to the field penetration time through the vacuum vessel. Experimentally it "-as demonstrated that field penetration is fast enough to move the plasma radially $5 \mathrm{~cm}$ in $10 \mathrm{~ms}$. Each passive flate has a toroidal gap for $\mathrm{OH}$ flux penetration. In Fig. 3, sets 1, 2, and 3 are for stabilizing the $n=0$ component with one saddle connection between top and bottom. The effect of these plates is expected to be relatively weak for moderately indented plasmas, increasing as the plasma approaches the plates with vertical motion. Set 5 is the main stabilizing compunent for both the $n=0$ and $n=1$ companents. To increase the effectiveness for $n=1$ stabilization, additional paths for current flow between the top and bottom plates are provided by eleven electrical conneciions nearly equally distributed in the toroidal direction. The mid-plane area is left open for NBI, RF couplers, and diagnostic access. Set 4 can be used for either $n=0$ stabilization or can be used for both $n=0$ and $n=1$ stabilization by connecting it to set 5 at eleven toroidal locations. This extended coverage configuration was first used to study the effectiveness of the passive stabilizer against the $n=1$ mode [2]. We presently use this extended coverage option for normal operation which effectively combines plates 4 and 5 as a stabilizer for both the $n=0$ and $\mathrm{n}=1$ modes.

As stated previously, the coupling between the active and the passive systems has a negative effect on the active control system. The passive system actually shields the plasma from the active coil[7]. If the magnitude of this coupling is excessive, active control of the plasma's vertical position cannot be achieved. During the design phase, the coupling between the active and passive systems is considered an important design parameter and great care is taken to minimize it.

Equations (7) and (8), for the explicit-z and integrated shell methods respectively, must be satisfied to allow active control of the plasma's vertical 
position. From Eq. (7), for the explicit-z method, we see that

$$
\left|M_{p s, a}\right|<\left|\frac{L_{p s} M_{a, p l}^{\prime}}{M_{p s, p l}^{\prime}}\right|
$$

which reduces to $\mathrm{M}_{\mathrm{ps, \textrm {2 }}}=14.5 \times 10^{-6}<25.7 \times 10^{-6}$ using parameter values from Table 1. Using Eq. (8), for the integrated shell method

$$
\left|M_{p s, a}\right|<\left|\frac{M_{a, p l}^{\prime} M_{p s, p l}^{\prime}}{M_{e x t, p l}^{\prime \prime}}\right|
$$

which reduces to $\mathrm{M}_{\mathrm{pb}, 2}=14.5 \times 10^{-6}<43.6 \times 10^{-6}$ using parameter values from Table 1. We see thas for the PBX-M device the condition on the coupling between the active and passive systems is easily satisfied for both methods of control.

\subsection{Eddy Current Patterns}

Eddy currents on the shell are measured by Rogowski coils on the eleven mid-plane electrical jumpers that connect the upper and lower plates of set 5. The effective bandwidth, including the necessary integrator, is $10 \mathrm{kHz}$ with a sensitivity of $\approx 10 \mathrm{~A}$. The eddy current pattern on the passive stabilizer due to plasma vertical motion is a saddle-like current with the polarity change occurring at the $\mathrm{OH}$ gap. It is possible to visualize the eddy current distribution by assuming that the current distribution is continuous rather than consisting of the eleven jumper currents. The conditions $\nabla \times \overrightarrow{\mathbf{B}}=\overrightarrow{\mathbf{I}}$ and $\mathrm{B}_{\mathrm{r}}=$ constant constrain the eddy current $\mathrm{I}_{\mathrm{pe}}(\phi)$ to be a linear function of toroidal angle, namely $\mathrm{I}_{\mathrm{pe}}(\phi)=\mathrm{I}_{\mathrm{D}}(\phi-\pi)$. An example of the eddy current as a function of toroidal position is shown in Fig. 4. In this case, the vertical position control was disabled at $t=400 \mathrm{~ms}$. As expected, the values of induced current are opposite in sign at $\phi=0_{+}$and $\phi=0_{-}$degrees relative to the $\mathrm{OH}$ gap. It is possible to extract the linear component, as a function of $\phi$, of the observed distribution. In the experiment, the difference between the current signals at $\phi=0_{+}$and $\phi=0_{-}$is taken and averaged to extract the $\mathbf{n}=0$ component. By averaging in this manner, it is possible to minimize the contributions from $n=1$ type MHD activity as reported in [2]. 


\subsection{Example of operation}

Figure $5 \mathrm{a}$ is a time sequence of the currents for a bean-shaped configuration discharge utilizing the passive shell currents to control the plasma vertical position. Prior to $t=0$ (data before $t=0$ is not shown), the $\mathrm{OH}$ current is ramped to $10 \mathrm{kA}$. At $\mathrm{t}=-16 \mathrm{~ms}$, the $\mathrm{OH}$ current begins a sharp decrease, producing a one turn voltage $(\approx 15 \mathrm{~V}$ in a vacuum) that initiates the plasma discharge. The vertical position control is turned on at $t=0 \mathrm{~ms}$ with Rogowski \#1 as the sensor. Initially the plasma cross section is circular, equilibrated only by the equilibrium field (EF) current (uniform vertical field). The elongation control trim field (T3) is snabled at $t=100 \mathrm{~ms}$, followed immediately by the indentation field (IF) to form the bean shape configuration. The divertor separatrix trimming current (T2) is added at $t=250 \mathrm{~ms}$, and the discharge achieves quasi-steady state at $t=350 \mathrm{~ms}$. The discharge is terminated at $\mathrm{t}=750 \mathrm{~ms}$ by lowering all of the shaping fields (T2, IF, T3, and DF).

As seen on the shell current (Rogowski \#1), the current between $t=0$ and $100 \mathrm{~ms}$ suddenly increases. This is presumably due to the asymmetric field produced by the high one-turn voltage required to initiate the discharge, which produces top/bottom asymmetric currents on the vacuum vessel and internal coil cases. When the primary shaping fields (IF and T2) are activated, a similar increase in the shell current is observed. Because the gain of the feedback system is optimized for the quasi-steady state period, we see high currents in the feedback system coil at 100 and $200 \mathrm{~ms}$.

The behavior of the flux at the shell surface is monitored at observation locations 3 and 4 in Fig. 3. The signals $\psi_{3}$ and $\psi_{4}$ in Fig. $5 \mathrm{~b}$ are the difference between the top and bottom flux signals at positions 3 and 4, respectively. During the quasi-steady state period, these two flux values show similar behavior. The magnitude of the computed flux difference at location 4 is closer to zero, indicating that the plasma surface is closer to being vertically centered at this radial position. On the other hand, the behavior at location 3 is similar but is shifted by $\Delta \psi \approx 1 \mathrm{mWb}$, indicating that at this radial position, the flux surface has slightly more vertical asymmetry.

The plasma vertical motion can be independently determined from sawteeth crash behavior measured by soft $x$-ray arrays viewing a poloidal crosssection of the plasma. Figure 6 shows that during the quasi-steady state period, the sawtooth inversion radius remains constant between 5 and $7 \mathrm{~mm}$ 
below the mid-plane. This is consistent with the observed flux signals $\psi_{3}$ and $\psi_{4}$. As shown in this example, the system is stable and the vertical position is maintained within $\pm 1 \mathrm{~mm}$

\section{Discussion}

Here, we discuss practical issues and merits for both the explicit- $z$ and integrated shell methods of vertical position control. One of the difficulties for the vertical position control is the excitation of unknown radial fields most probably due to (1) asymmetric eddy currents due to asymmetries in the supporting structure, or (2) asymmetric fields caused by misaligned poloidal field coils. Furthermore, misalignment of field sensors can add to the complexity of the system. We first discuss the explicit-z approach.

Typically, at least for most present tokamaks, the vertical position control feedback system has one active power supply. The control variable is constructed as follows:

$$
\alpha \stackrel{\text { def }}{=} \sum_{i} D_{i} \Delta \psi_{i}^{\text {obs }}
$$

where $\Delta \psi_{i}^{\text {obs }}$ is the observed difference in poloidal flux at a given major radius at symmetric locations above and below the mid-plane. Depending on the choice of $\left\{D_{i}\right\}, \alpha$ might represent the vertical position of the outermost magnetic flux surface, an averaged observed magnetic flux, or a magnetic flux value of the control variable extrapolated towards the plasma surface. The best choice for $\left\{D_{i}\right\}$ depends on the locations where the flux is observed, the location of the active coil system, the geometry of the passive system, and the shape of the plasma. The definition of the control variable, $\alpha$, and the choice of $\left\{D_{i}\right\}$ have been proposed by various groups for their respective devices. For example, in the bean shaped configuration it has been suggested that the system can be made more stable if the positions of the flux sensors cross the magnetic surface and are far away from the equilibrium field coils[9]. One possible method of formulating the flux function would be to use numerical equilibrium results to parameterize the dependence[1].

The experimental determination of the vertical location of the plasma centroid appears to be straightforward. However, the experimentally observed 
flux, $\Delta \psi_{\text {exp }, i}^{o b s}$, is contaminated by "non-ideal" contributions $\delta \psi_{\mathrm{j}}^{\mathrm{obs}}$.

$$
\Delta \psi_{e x p, i}^{o b s}=\Delta \psi_{i}^{o b s}+\delta \psi_{i}^{o b s}
$$

These non-ideal sources of flux are due to

1. Poloidal and/or toroidal misalignment of observation flux loops.

2. DC asymmetric fields due to imperfect alignment of poloidal field coils and toroidal field windings.

3. Asymmetric eddy currents on the metallic structures related to plasma horizontal motion and the poloidal flux swing.

The magnitude of these non-ideal components of flux can be comparable to that produced by plasma motion. To achieve effective control, we must compensate for these sources of flux in the feedback system. Some non-ideal components are proportional to the poloidal field currents and eddy currents produced by time derivatives of poloidal field currents, i.e.,

$$
\delta \psi_{i}^{o b s, p f}=\sum_{j} E_{i, j} I_{j}+\sum_{j} F_{i, j} \dot{I}_{j}
$$

The observed value of the control variable $\left(\alpha^{\circ}\right)$ without compensation is

$$
\alpha^{o}=\sum_{i} D_{i} \Delta \psi_{i}^{o b s}+\sum_{i} \sum_{j} D_{i} E_{i, j} I_{j}+\sum_{i} \sum_{j} D_{i} F_{i, j} \dot{I}_{j} .
$$

As stated previously, we must compensate for $\delta \psi_{i}^{\text {obs }}$ in the feedback system. In practice, the compensation process can be quite tedious, and typically only those terms proportional to PF currents are compensated. Compensation of sources proportional to derivatives of the PF currents (i.e., eddy currents) is considerably more difficult and usually is not successful. In some cases, multiple redundant magnetic measurements, combined with averaging techniques are used to deal with this problem.

For some configurations inclusion of a time derivative term in the control may be necessary to achieve a stable response in the explicit-2 feedback scheme $[6,8]$. The inclusion of the derivative term helps by advancing the phase of the system. Unfortunately, the bandwidth of the system must be 
limited to maintain reasonable noise immunity. This tradeoff increases the stability but degrades the response capability of the system.

For the integrated shell approach, the induced current on the passive shell $I_{p s}$ is the quantity we want to control, so that the control variable becomes

$$
\alpha \stackrel{\text { def }}{=} I_{p s} \text {. }
$$

Again, as in the explicit-z formulation, $I_{p s}$ will contain non-ideal components so that

$$
I_{p s}^{\exp }=I_{p s}+\delta I_{p s}
$$

where $I_{p s}^{\exp }$ is the observed value of the control variable $I_{p s}$ and $\delta I_{p s}$ represents non-ideal currents attributable to sources similar to $\delta \psi_{i}^{\text {obs }}$ in $\mathrm{Eq}(13)$.

Some of these non-ideal effects are automatically compensated simply by our choice of $I_{p s}$ as the control variable. As an example, consider the localized eddy current patterns $\delta \mathrm{J}_{\mathrm{ps}}^{\mathrm{n}, \mathrm{m}}$ (higher $\mathrm{n} / \mathrm{m}$ components) related to unidentifiable local eddy fields. Averaging this over the shell surface results in $\left\langle\delta \mathrm{I}_{\mathrm{ps}}^{\mathrm{n}, \mathrm{m}}\right\rangle \approx 0$. Thus the current through the saddle-connected passive shell is a global quantity representing the top/bottom asymmetric $n=0$ current.

If the shell is not ideal, eddy currents with an $n=0$ character can be produced by time-varying components of the equilibrium field. However, this $n=0$ current induced on the shell is no different from that resulting from plasma motion. The feedback system merely acts to minimize the resulting radial field and compensation is achieved. On the other hand, effects of DC asymmetric fields must still be compensated, otherwise the effective value of the control variable will be offset from the target value.

The fact that a derivative term is not required for effective control is central to the success of this method. The reason for this is that the current on the passive shell is proportional to the derivative of the fur on the passive stabilizer (see Eq. 3). In principle other devices could implement a similar control if they can provide enough flux loops to accurately represent the flux on the passive stabilizer. They could then implement Eq. 3 by taking the derivative of their flux quantity if they knew the resistance of the passive stabilizer accurately. There would still remain the problem of taking the derivative of noisy data that would necessitate some action that would necessarily reduce the systems bandwidth. For machines that would like to 
use the passive shell but do not have a toroidal gap, Rogowski coils could be used to measure asymmetric currents on the shell or an additional poloidally wound passive saddle coil could be used to measure this current.

Again, for simplicity, a double-null configuration has been assumed with $\alpha^{t}=I_{p s}=0$, i.e., we want to hold the plasma symmetrically on the midplane. An asymmetric configuration such as a single-null divertor can be stabilized in a similar manner by offsetting $\alpha^{t}$ proportional to the plasma current. The passive shell in this case should be designed so as to minimize coupling between the shell and the poloidal field coils.

\section{Summary}

We have demonstrated the applicability of the integiated shell concept to vertical position control. The key is the usage of the $n=0$ component of the shell current, $\mathrm{I}_{\mathrm{ps}}$. By using the shell current, we have been able to effectively control the vertical position of the plasma without actually determining its position. Operationally, DC compensation and controller tuning were greatly simplified, and the system was able to maintain control over a wide range of plasma discharge conditions without retuning or recompensating. Elimination of the derivative term in the control law allows us to operate the system with increased bandwidth (when compared to operation with the explicit-z method) and reduces the amount of noise in the system. Overall operation was improved over previous implementations u.ing the explicit-z method.

Because the geometry of the shell is designed to optimize the coupling between the shell and the plasma vertical motion, the shell eddy current $I_{p s}$ is naturally a good global measure of the vertical motion. In principle, local flux measurements can serve as sensors for similar flux-conserving effects on the shell surface. However, the accurate determination of the averaged flux on the shell surface with local fivin observativins is diffeult in prastics. To accomplish the measurement, multiple observation points, an accurate functional parameterization of the flux values, and an effective magnetic field compensation scheme are needed. The additional complexity adds uncertainty in the control variable and is a source of error in the control system.

Improvements in vertical position control are related to more accurate measurement of the eddy current patterns associated with plasma vertical position. Better determination of the eddy currents plays a fundamental role 
in the improvement of any scheme for disruption avoidance. These improvements may benefit larger future devices such as TPX and ITEit.

\section{Acknowledgments}

We would like to thank the members of the PBX-M group for their continuing encouragement and support. We would especially like to thank Drs. R. Bell, R. Kaita, H. Kugel, and H. Takahashi for their insightful comments. The detailed comments provided by Mr. R. Woolley for improvements in the manuscript also deserve special mention. Additionally, we would like to thank Mr. G. Gettelfinger and the PBX-M technical staff for the outstanding job they perform operating and maintaining the $P B X-M$ device. This work was supported by the United States Department of Energy, under contract No. DE-AC02-76-CHO-3073. 
Table 1: Circuit and magnetic field parameters for the PBX-M device.

$\begin{array}{rll}\mathrm{L}_{\mathrm{ps}} & =9.7 \mu \mathrm{H} \\ \mathrm{R}_{\mathrm{ps}} & =62 \mu \Omega \\ \mathrm{I}_{\mathrm{a}} & =2.1 \mathrm{mH} \\ \mathrm{R}_{\mathrm{a}} & =13.8 \mathrm{~m} \Omega \\ \mathrm{M}_{\mathrm{ps}, \mathrm{a}} & =14.5 \mu \mathrm{H} \\ \mathrm{M}_{\mathrm{ps}, \mathrm{pl}}^{\prime} & =7.7 \mu \mathrm{H} / \mathrm{m} \\ \mathrm{M}_{2, \mathrm{pl}}^{\prime} & =20.4 \mu \mathrm{H} / \mathrm{m} \\ \mathrm{M}_{\mathrm{ext}, \mathrm{pl}}^{\prime \prime} & =-3.6 \mu \mathrm{H} / \mathrm{m}^{2}\end{array}$


Table 2: Coefficients of the characteristic equation given PBX-M parameters.

\begin{tabular}{|l|ll|}
\hline Integrated Shell Control & \multicolumn{2}{|c|}{ Explicit-z Control } \\
\hline $\mathrm{A}=-0.70$ & $\mathrm{~A}=-0.70$ \\
$\mathrm{~B}_{0}=1.48$ & $\mathrm{~B}_{0}=1.48$ \\
$\mathrm{~B}_{1}=-1428.46$ & $\mathrm{~B}_{1}=-1183.57$ \\
$\mathrm{C}_{0}=41.85$ & $\mathrm{C}_{0}=41.85$ \\
$\mathrm{C}_{1}=0.0$ & $\mathrm{C}_{1}=-17222.10$ \\
\hline
\end{tabular}




\section{Appendix A. Form of the Characteristic Equation}

The characteristic equation of the system of equations 1 through $4\left(K_{d}=0\right)$ can be written as

$$
f(s)=A s^{2}+B s+C=0
$$

where $s$ is the variable of Laplace transformation. The coefficients $A, B$, and $\mathrm{C}$ are

$$
A=1+\frac{M_{p s, p l}^{\prime} l^{2}}{M_{e x t, p l}^{\prime \prime} L_{p s}}+\frac{M_{a, p l}^{\prime}{ }^{2}}{M_{e x t, p l}^{\prime \prime} L_{a}}-2 \frac{M_{p s, a} M_{p s, p l}^{\prime} M_{a, p l}^{\prime}}{M_{e x t, p l}^{\prime \prime} L_{a} L_{p s}}-\frac{M_{p s, a}^{2}}{L_{a} L_{p s}}
$$

$B=B_{p s}, B_{z}$ for the integrated shell and explicit-2 approaches respectively

$$
\begin{aligned}
B_{z}= & \frac{R_{p s}}{L_{p s}}\left[1+\frac{M_{a, p l}^{\prime}{ }^{2}}{L_{a} M_{e x t, p l}^{\prime \prime}}+\frac{M_{p s, p l}^{\prime}{ }^{2} R_{a}}{L_{a} R_{p s} M_{e x t, p l}^{\prime \prime}}+\frac{L_{p s} R_{a}}{R_{p s} L_{a}}\right] \\
& -\frac{K_{p}}{L_{a} L_{p s}}\left[\frac{M_{p s, a} M_{p s, p l}^{\prime}}{M_{e x t, p l}^{\prime \prime}}-\frac{L_{p s} M_{a, p l}^{\prime}}{M_{e x t, p l}^{\prime \prime}}\right] \\
B_{p s}= & \frac{R_{p s}}{L_{p s}}\left[1+\frac{M_{a, p l}^{\prime}{ }^{2}}{L_{a} M_{e x t, p l}^{\prime \prime}}+\frac{M_{p s, p l}^{\prime}{ }^{2} R_{a}}{L_{a} R_{p s} M_{e x t, p l}^{\prime \prime}}+\frac{L_{p s} R_{a}}{R_{p s} L_{a}}\right] \\
& +\frac{K_{p}}{L_{a} L_{p s}}\left[M_{p s, a}+\frac{M_{a, p l}^{\prime} M_{p s, p l}^{\prime}}{M_{e x t, p l}^{\prime \prime}}\right]
\end{aligned}
$$

and $\mathrm{C}=\mathrm{C}_{\mathrm{ps}}, \mathrm{C}_{\mathbf{z}}$ for the integrated shell and explicit-z approaches respectively

$$
\begin{gathered}
C_{z}=\frac{R_{p s} R_{a}}{L_{p s} L_{a}}+K_{p} \frac{R_{p s} M_{a, p l}^{\prime}}{L_{a} L_{p s} M_{e x t, p l}^{\prime \prime}} \\
C_{p s}=\frac{R_{p s}}{L_{p s}} \frac{R_{a}}{L_{a}}
\end{gathered}
$$

Given our definitions for current reference directions etc. $A<0$ and, in the limit as $K_{p} \rightarrow 0, B>0$ and $C>0$. 


\section{References}

[1] O. Gruber et al., Plasma Phys. and Control. Fusion 35 (1993).

[2] M. Okabayashi et al., in Europhysics Conference Abstracts, 18th European Conf. on Control. Fusion and Plasma Physics, Berlin 1991 (EPS, Berlin, 1991), Contributed Papers, Part I, p. I-133.

[3] H. W. Kugel et al., Proceedings of the IEEE/NPSS, IEEE 15th Symposium on Fusion Engineering, Hyannis, Oct. 1993.

[4] W. M. Nevins et al., Plasma Phys. and Control. Fusion Research, 14th Conf. Proc. IAEA, Wurzburg, Germany 1992 (IAEA, Wurzburg, 1992).

[5] C. M. Bishop Plasma Physics and Controlled Fusion, 31 (1989).

[6] E. A. Lazarus et al Nuclear Fusion 30, 111 (1990).

[7] S. C. Jardin et al. Nuclear Fusion 22, 1095 (1982).

[8] R. E. Hatcher et al. Proceedings of the IEEE/NPSS, IEEE 13th Symposium on Fusion Engineering, Knoxville, Oct. 1989.

[9] S. C. Jardin et al., Nuclear Fusion 27, 569 (1987). 


\section{Figures}

Fig. 1. Schematic representations of the explicit-z and integrated shell vertical position control schemes.

Fig. 2. Behavior of the roots to the characteristic equation for the explicit-z and integrated shell methods as the gain $K_{p}$ is varied.

Fig. 3. Explicit-z and integrated shell methods applied to PBX-M. Both methods share the active power supply and coil system. In the explicit-z method we measure the poloidal flux on both sides of the passive stabilizer. For the integrated shell method the measurement is of the $n=0$ component of the passive shell current.

Fig. 4. Eddy current on the passive stabilizer with vertical plasma motion.

Fig. 5. Quantities relevant to vertical position for a typical PBX-M plasma discharge utilizing integrated shell control. (a) Plasina and poloidal field currents. (b) $n=0$ passive current Rogowski signal, flux loop signal, and active power supply current.

Fig. 6. Vertical position of the plasma discharge, with integrated shell control, derived from soft $\mathrm{x}$-ray sawtooth inversion radius data. 


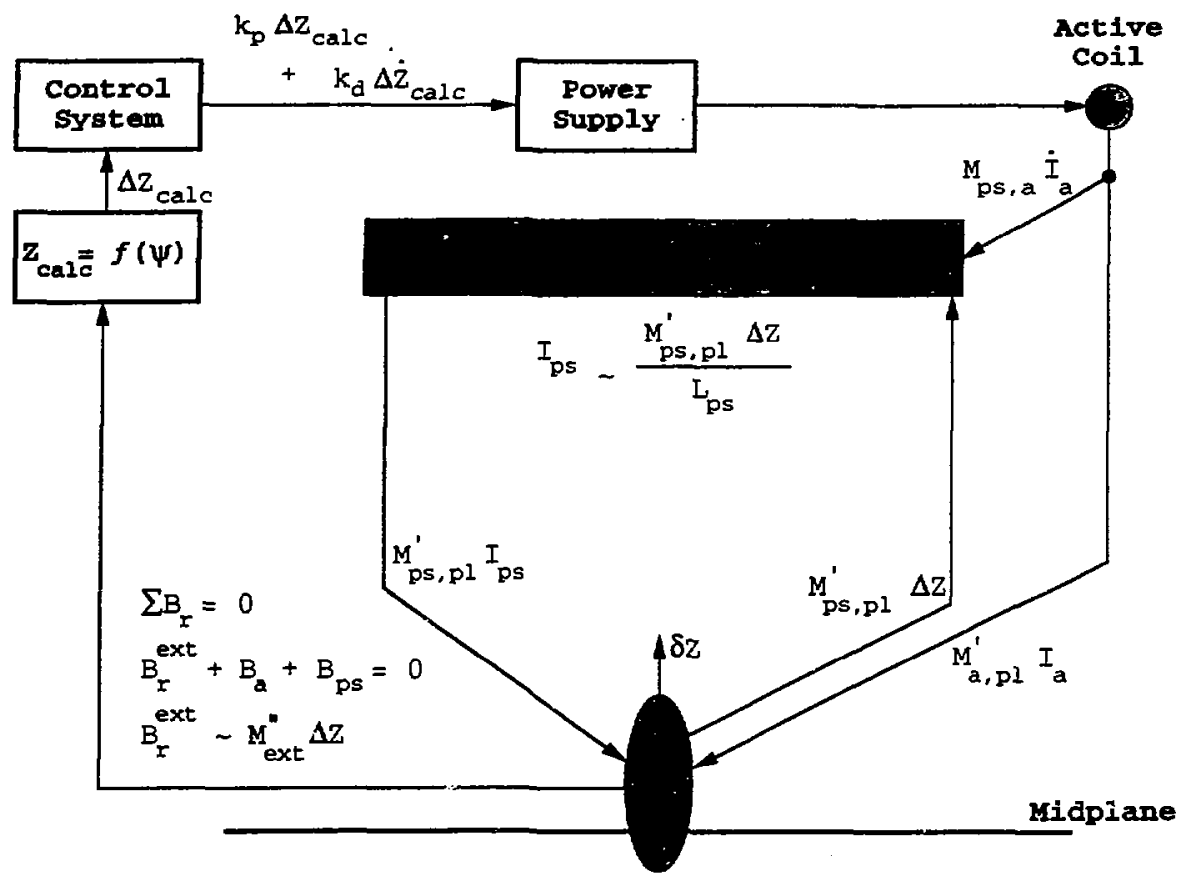

Fig. 1a Block diagram of the explicit-z method.

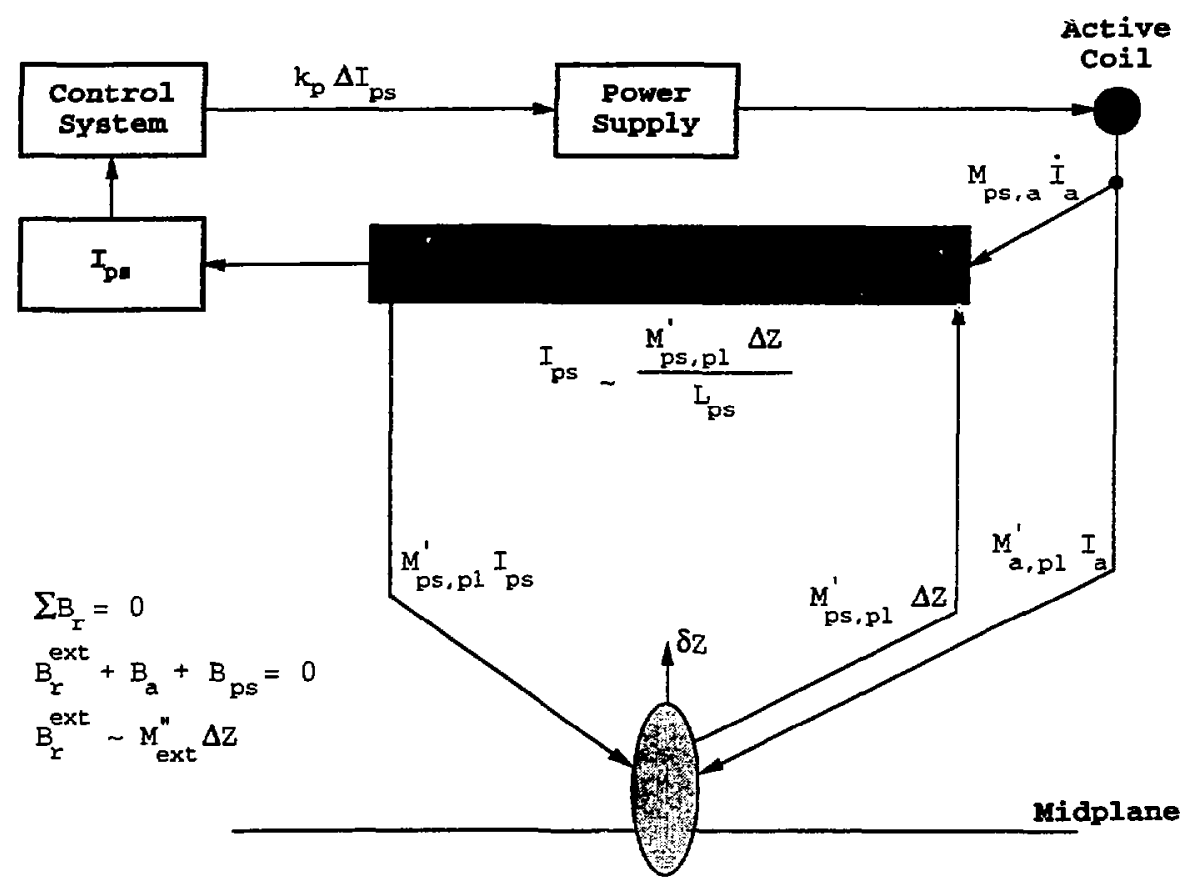

Fig. 1b Block diagram of the integrated shell method. 


\section{Explicit-z Control}

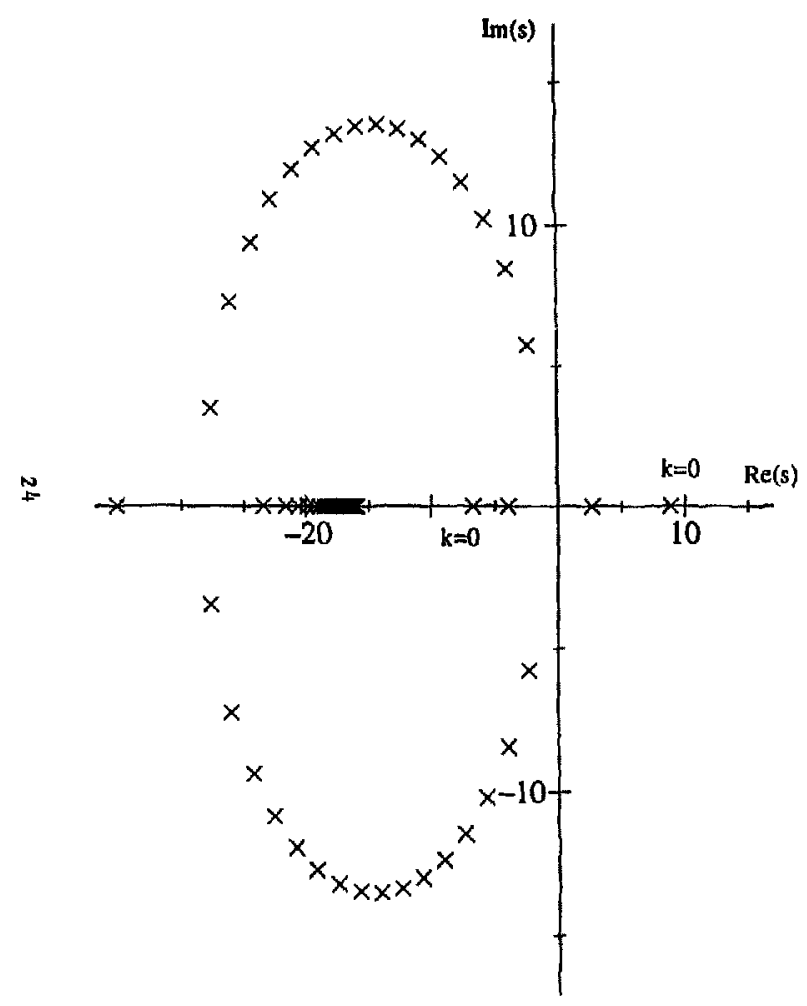

Passive Shell Control

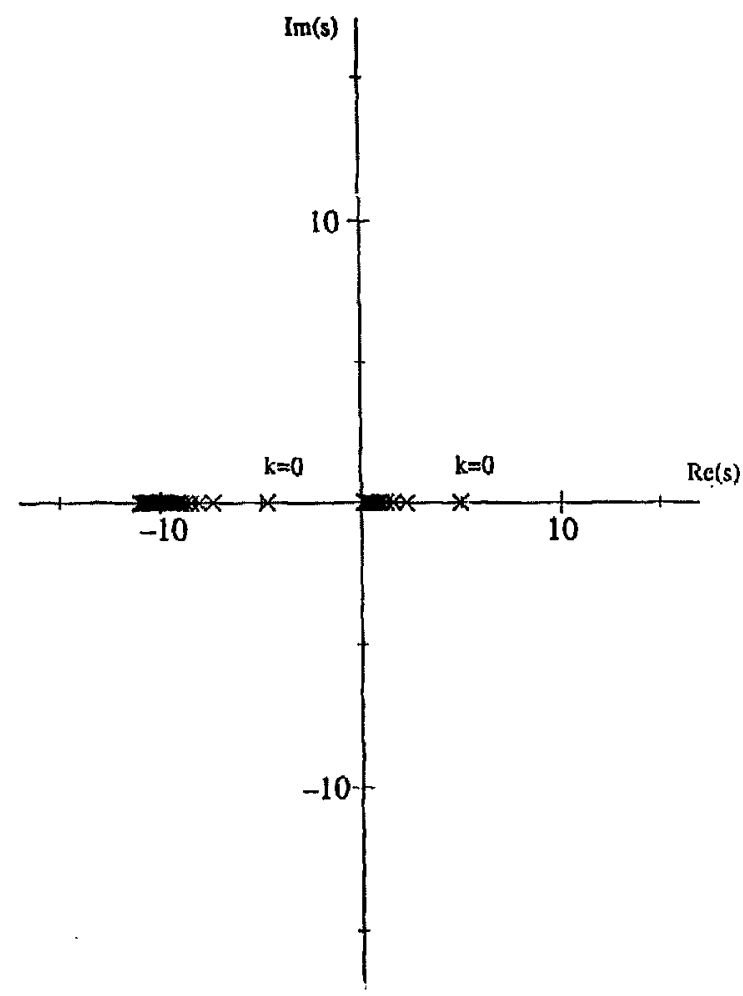

Fig. 2 


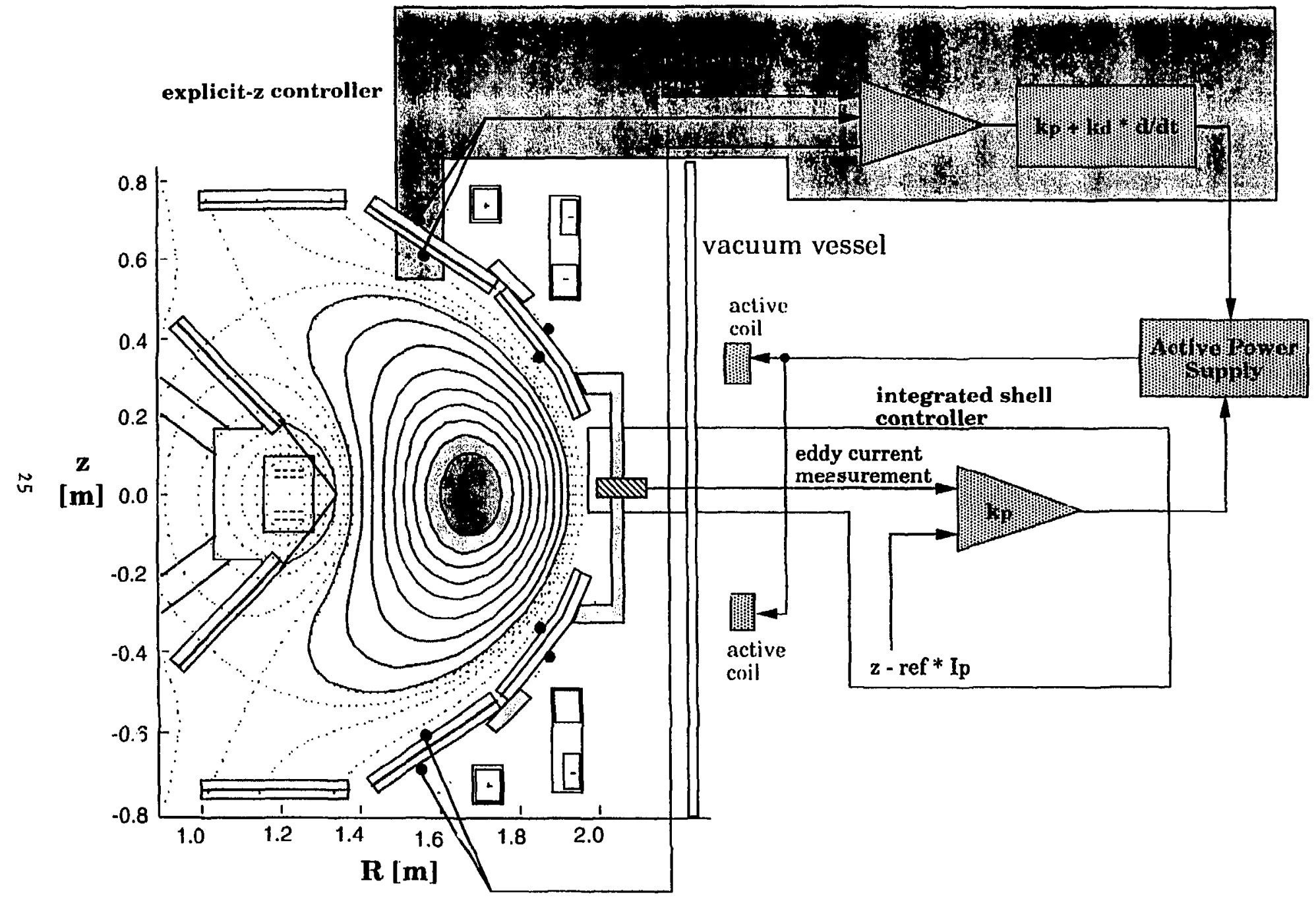

Fig. 3 


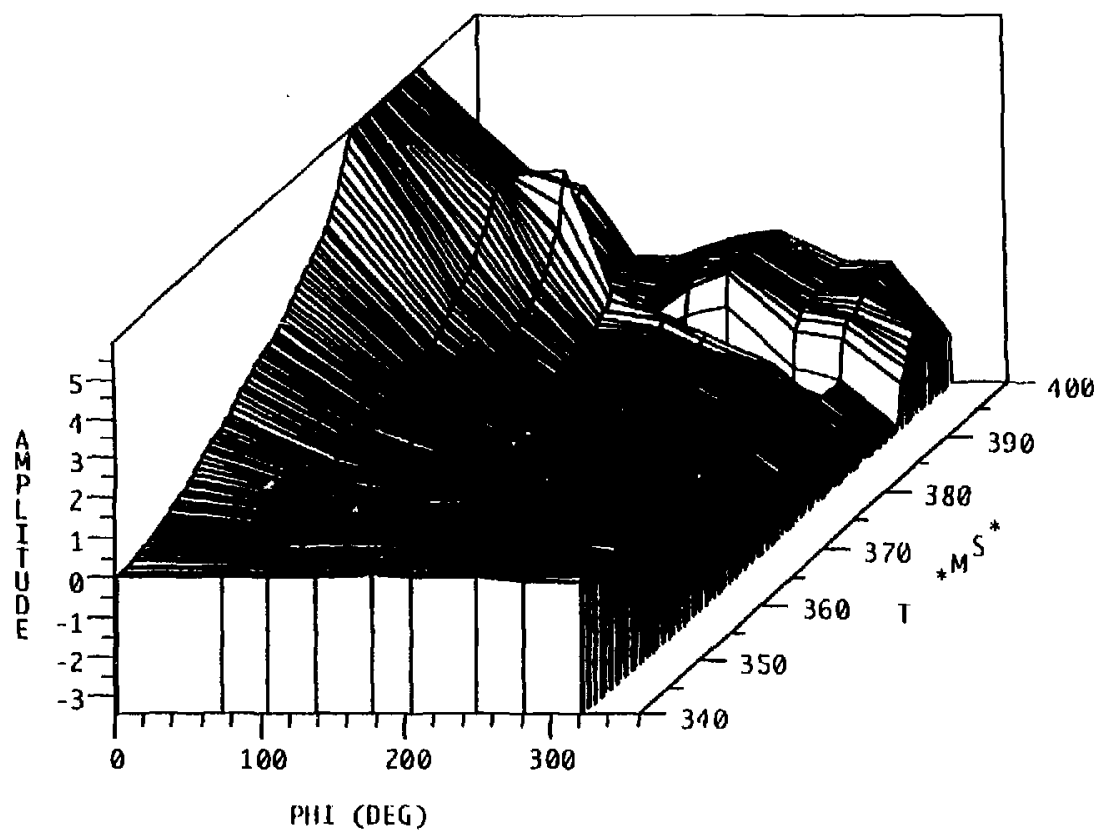

Fig. 4 


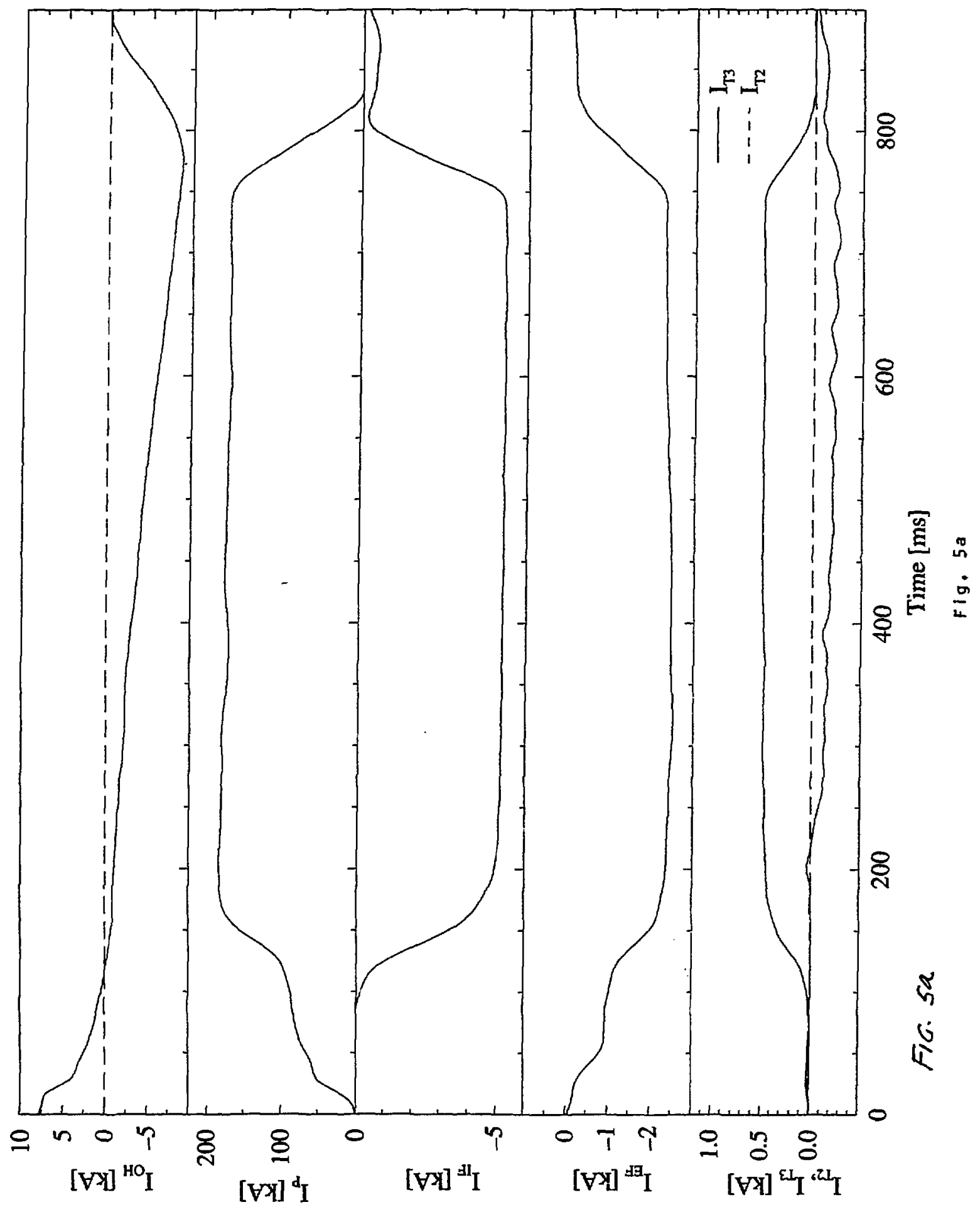




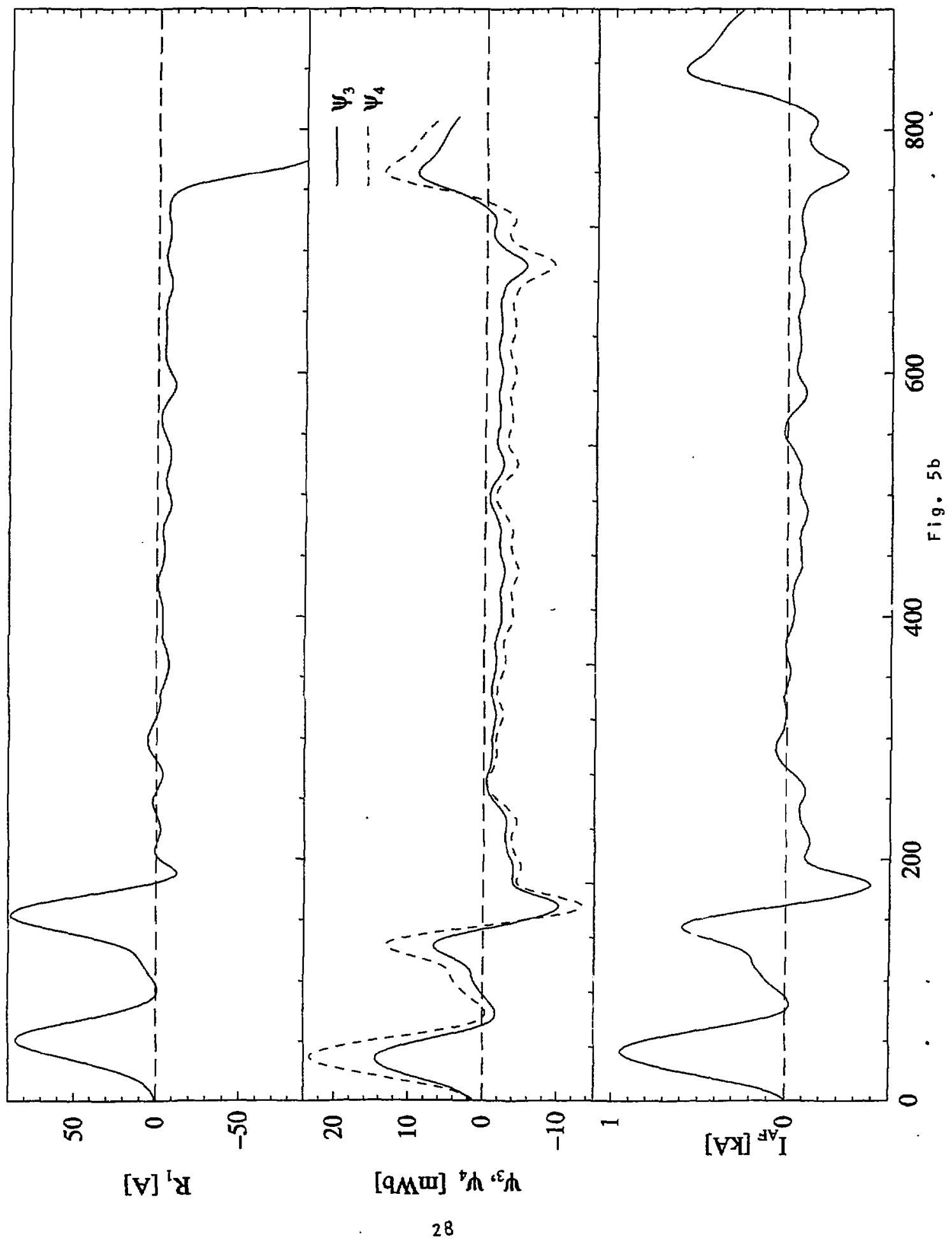




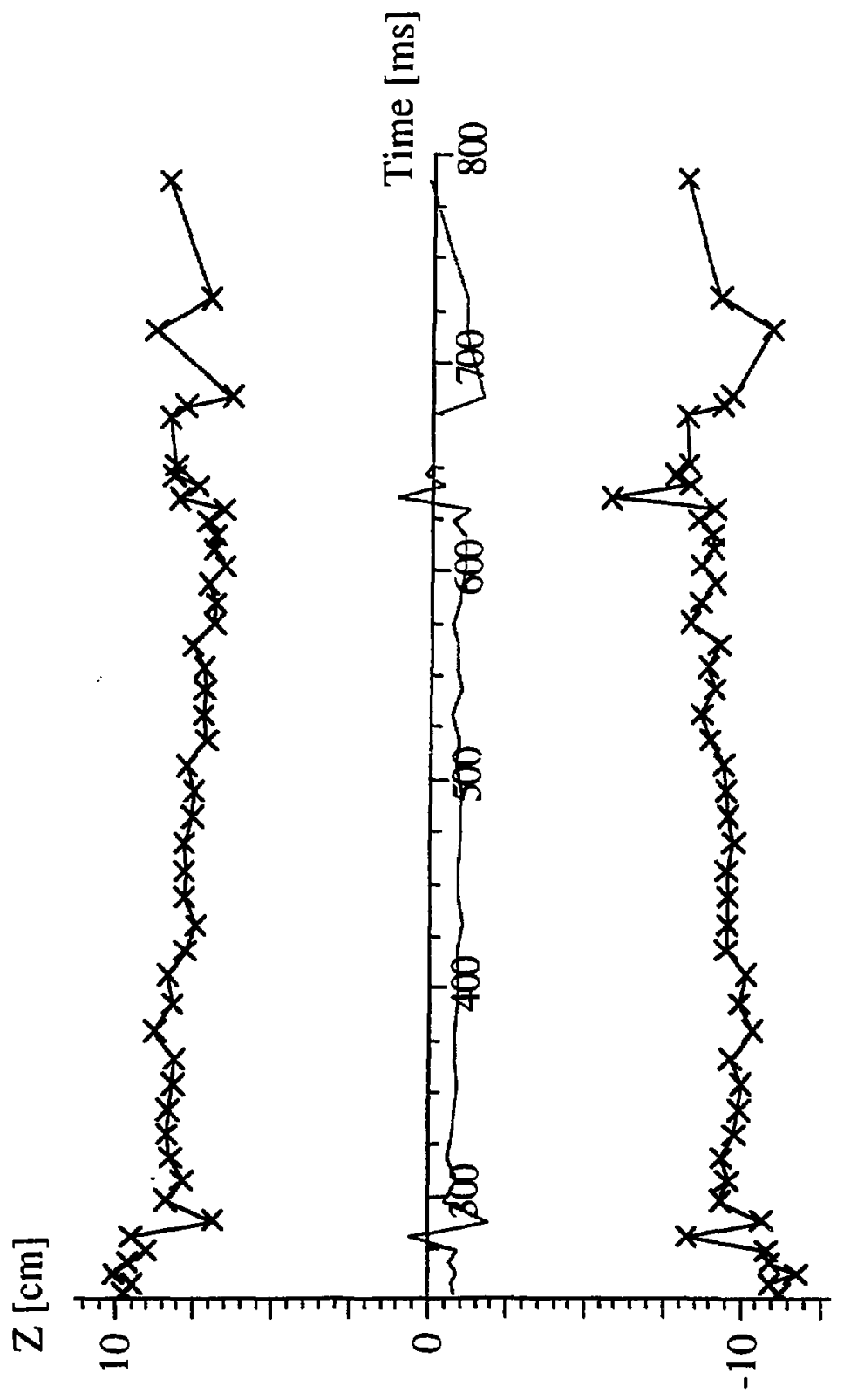




\section{EXTERNAL DISTRIBUTION IN ADDITION TO UC-420}

Dr. F. Paoloni, Univ, of Wollongong, AUSTRALlA

Prof. R.C. Cross, Univ. of Sydney, AUSTRALIA

Plesma Fesench Lib., Australion Nat Univ., AUSTRALlA

Prot. I.R. Jones, Finders Univ, AUSTRALIA

Prof. F. Cep, Inst. tor Theoretical Phyzies, AUSTRIA

Prol. M. Heindier, insilut for Theoretische Physik, AUSTRIA

Prol. M. Goossens, Astronomisch InctituUt, BELGIUM

Ecole Royda Mitaire, Lob. de Phy. Plaemas, BELGIUM

Commistion-Europeen, DG. XII-Fueion Prog., BELGUM

Prof. R. Bouciqut, Aijkeuniversibit Cent, BELGIUM

Dr. P.H. Sakanke, Inatuno Fisica, BRUZIL

Prof. Dr. I.C. Nacioimento, Instituto Fisica, Seo Paulo, BRAZIL Instiuto Necionel De Pesquisas Espaciais-INPE, BRAZL

Documents Olice, Alomic Eneroy of Cenada LUd., CANADA

Ms. M. Morin, CCFMTokamak de Verennes, CANADA

Dr. M.P. Bestyngki, MPB Technologies, Inc., CANADA

Dr. H.M. Skarsgard, Univ. of Sackakhewen, CANADA

Prof. J. Teictmann, Univ, of Montreal, CANADA

Prot. S.R. Sreenivaten, Univ. of Culgary, CANADA

Prof. T.W. Johnston, INRS-Energie, CANADA

Dr. R. Bolton, Centre canadien de fusion magnétique, CANADA

Dr. C.R. James, Univ. of Aborta, CANADA

Dr. P. Lukic, Komenského Universzits, CZECHO-SLOVAKIA

The Libraian, Cutham Laboratory, ENGLAND

Libray, R61, Rutherford Applaton Laboratory, ENGLAND

Nrs. S.A. Huttchinson, JET Library, ENGLAND

Dr. S.C. Sheme, Univ. of South Pacilic, FLII ISLANDS

P. Mahoonen, Univ. of Helsinki, FINLAND

Prof. M.N. Busesc, Ecole Polybochnique, FRANCE

C. Houttot, Leb. de Physique des MTieux lonisés, FRANCE

J. Radet, CENCADARACHE - Bat 505, FRANCE

Prol. E. Economou, Unir. of Crete, GREECE

Ms. C. Rinni, Univ. of loamina, GREECE

Preprint Library, Hungarian Academy of Sci., HUNGARY

Dr. B. DasGupta, Saha Inst. of Nuclear Physics, INDIA

Dr. P. Kaw, Inst. for Plasma Research, INDIA

Dr. P. Rocenew, lereel inst of Technology, ISPAEL

Librecien, Intomationd Certer for Theo Physics, ITALY

Nies C. De Palo, Associnziono EURATOMENEA, ITALY

Dr. G. Grosso, lotituto di Fision del Plesma, ITALY

Prof. G. Postungos, bstituo Gas lonizzati Del Cnr, ITALY
Dr. H. Yemato, Tochiba Ras \& Dovel Center, JAPAN

Prol. I. Kmwakami, Hiroshima Univ., JAPAN

Prol. K Nishiknwa, Hiroshima Univ. JAPAN

Lorevien, Nake Fusion Rosearch Establithment, JAERI, JAPAN

Director, Japen Alomic Eneryy Pesearch Inst, JAPAN

Prof. S. Itoh, Kyushu Unin., JAPAN

Peseanch Info. Ctr., National Instit for Fusion Science, JAPAN

Prof. S. Tenaxa, Kyov Univ., JAPAN

Lbrary, Kyoto Univ., JAPAN

Prol. N. Inowe, Univ, of Tokyo, JAPAN

Secretary, Plasma Saction, Electrotachnical Lab., JAPAN

Dr. O. Mieraj, Kumamoto Inst. of Technology, JAPAN

Dr. G.S. Loe, Konen Basic Sci. Cr., KOREA

J. Hyeon-Sook, Korea Atomic Energy Posearch Inst, KOREA

D.I. Choi, The Korea Adv. Inst of Sci. Tech., KOREA

Prof. B.S. Lithy, Univ. of Weikato, NEW ZEALAND

Inst of Physies, Chinese Acad Sci PEOPLE'S REP. OF CHINA

Libray, Inst of Plasma Physics, PEOPLE'S REP. Of CHINA

Tsinghua Univ. Library, PEOPLE'S REPUBLIC OF CHINA

2. Li, S.W. Inst Physics, PEOPLE'S REPUBLC OF CHINA

Prof. J.A.C. Cabral, Instituto Superior Tecnico, PORTUGAL.

Prof. MA. Hellberg, Univ. of Natal, S. AFRICA

Prof. D.E. Km, Pohang Inst. of Sci. \& Tech., SO. KOREA

Prol. C.I.E.M.A.T, Fusion Division Library, SPAN

Dr. L Stentio, Univ. of UMEA, SWEDEN

Library. Royal Inst. of Technology, SWEDEN

Prot. H. Wihetmson, Chalmers Univ. of Tech., SWEDEN

Contre Phys. Des Plasmas, Ecole Polytech, SWITZEPLAND

Bibliothek, Inst Voor Plasma-Fysica, THE NETHERLANDS

Asst. Prot. Dr. S. Cekir, Middle East Toch. Univ. TURKEY

Dr. V.A. Gulkhikh,Sci. Res. Inst. Electrophys.I Apparatus, USSR

Dr. D.D. Ayutov, Siberian Branch of Acadomy of Sai., USSR

Dr. G.A. Eliscev, I.Y. Kurchatov Inst. USSR

Librerian, The Ukr.SSR Academy of Sciences, USSR

Dr. LM. Kovizhnykh, Inst. of Generd Phycics, USsR

Komlortchungsanlege GmbH, Zentralbibliothek, W. GERMANY

Bibliothok, Inst. Fir Ptosmatortehung, W. GERMANY

Prof. K. Schindler, Puht-Universitt Bochum, W. GERMANY

Dr. F. Wagner, (ASDEX), Max-Punck-lnstitul, W. GERMANY

Librarion, Max-Planck-Intututu, W. GEAMANY 